This item was submitted to Loughborough's Research Repository by the author.

Items in Figshare are protected by copyright, with all rights reserved, unless otherwise indicated.

\title{
Effect of hybrid reinforcement based on precipitated silica and montmorillonite nanofillers on the mechanical properties of a silicone rubber
}

\section{PLEASE CITE THE PUBLISHED VERSION}

http://dx.doi.org/10.1002/pen.23734

\section{PUBLISHER}

(c) 2013 Society of Plastics Engineers. Published by Wiley.

\section{VERSION}

AM (Accepted Manuscript)

\section{PUBLISHER STATEMENT}

This work is made available according to the conditions of the Creative Commons Attribution-NonCommercialNoDerivatives 4.0 International (CC BY-NC-ND 4.0) licence. Full details of this licence are available at: https://creativecommons.org/licenses/by-nc-nd/4.0/

\section{LICENCE}

CC BY-NC-ND 4.0

\section{REPOSITORY RECORD}

Ismail, Nik I. Nik, Ali Ansarifar, and Mo Song. 2016. "Effect of Hybrid Reinforcement Based on Precipitated Silica and Montmorillonite Nanofillers on the Mechanical Properties of a Silicone Rubber". figshare. https://hdl.handle.net/2134/21473. 
Effect of hybrid reinforcement based on precipitated silica and montmorillonite nanofillers on the mechanical properties of a silicone rubber

N I Nik Ismail*, A Ansarifar** and M Song**

*Advanced Rubber Technology Unit, Technology and Engineering Division, Rubber Research Institute Malaysia (RRIM), 47000 Sungai Buloh, Selangor Darul Ehsan, Malaysia

**Materials Department, Loughborough University, Leicestershire, LE11 3TU, UK 


\title{
Effect of hybrid reinforcement based on precipitated silica and
}

montmorillonite nanofillers on the mechanical properties of a silicone rubber

\author{
N I Nik Ismail*, A Ansarifar** and M Song**
}

*Advanced Rubber Technology Unit, Technology and Engineering Division, Rubber Research Institute Malaysia (RRIM), 47000 Sungai Buloh, Selangor Darul Ehsan, Malaysia

**Materials Department, Loughborough University, Leicestershire, LE11 3TU, UK ABSTRACT

Silicone rubber (SR) nanocomposites containing precipitated silica (PS), montmorillonite (MMT) and PS/MMT hybrid fillers were prepared through melt-mixing technique. In the SR/PS/MMT nanocomposite, the hybrid filler weight ratio was increased progressively from 0.4 to 1.7 while keeping the MMT weight constant. The viscosity, cure characteristics and mechanical properties of the nanocomposites were subsequently measured. The optimum cure time increased and the scorch time and rate of cure decreased. Furthermore, when the hybrid filler weight ratio was raised to its optimum, the tensile strength, Young's modulus, modulus at 100\% and 300\% elongation (M100 and M300), elongation at break, stored energy density at break and hardness of the nanocomposite improved. The stress-strain properties of the nanocomposite with the hybrid filler improved at high deformation in comparison with those containing the PS and MMT fillers. The MMT filler exfoliated in the SR/MMT nanocomposite but did not in the nanocomposites containing the hybrid filler. Notably, the mechanical properties of the nanocomposite benefitted from the hybrid filler. This was due to the filler-filler and filler-rubber network formation in the rubber by the PS particles. Finally, effect of the PS, MMT and hybrid fillers on the energy loss or hysteresis of the rubber was measured. 


\section{INTRODUCTION}

Nanofillers are a class of new generation reinforcing fillers in elastomer, which have at least one dimension in a nanometre scale. It can be found in varying shapes such as particle, layer and fibre. The decrease in particle diameter, layer thickness, or fibrous material diameter from micrometer to nanometre, yields a large contribution to the surface area and high aspect ratio (length to diameter) of the nanofillers which are important for filler reinforcement of rubber. Owing to these unique features, nanofillers such as layer silicates [1-6], carbon nanotubes [7-9], nanosilica [10-12] and exfoliated graphene [13-14] have been intensively researched as a potential reinforcing agent in rubber. Several examples of reviews [15-18] suggest that the nanofillers mentioned above are a promising reinforcing agent to improve mechanical properties of rubber particularly at low filler loading.

For instance, natural rubber filled with 6 parts per hundred rubber by weight (phr) exfoliated layered silicates had similar hardness to the vulcanizates reinforced with 14 phr of carbon black (CB) (N330) and 35 phr of silica (Hi-Sil 233), respectively [5]. On the other hand, the inclusion of very small amounts of multi wall carbon nanotubes (MWNTs) showed a significant improvement in the mechanical properties and conductivity of silicone rubber [9]. The elastic modulus and tensile strength were improved by $120 \%$ in comparison with the pure rubber when 0.3 phr MWNTs was added. 
The study also demonstrated that only 0.05 phr of MWNTs was required to form a conductive interconnecting filler network.

In line with the current research on rubber nanocomposites, there has been much interest in developing hybrid reinforcement in rubber based on a combination of two different types of nanoparticles or of nanoparticles with conventional fillers such as carbon black and silica [19-22]. This is because the adverse effects of one nanofiller can be diluted by adding a second filler that could balance the properties of the filled rubber. More interestingly, the hybrid fillers have shown to give a synergy reinforcing effect to the rubber properties and at the same time, the benefits from the individual fillers were still retained [19-22].

For instance carbon black was added to styrene-butadiene-rubber (SBR) filled with MWNTs with the aim of reducing the high cost of MWNTs [19]. Some synergistic properties were obtained which resulted from nano effect interaction. It has been demonstrated that the hybrid filler in SBR exhibited better reinforcement by about $70 \%$ to $122 \%$ higher in tensile stress as compared to the SBR filled with MWNTs alone. At the same time, the addition of nanotube to the SBR/CB nanocomposite improved the electrical conductivity through a formation of conducting path between CNTs and CB aggregates. Ideally, a combination of CB can dilute the high cost of MWNTs without compromising the final performance of the rubber nanocomposite. 
$\mathrm{Qu}$ and co-workers [20] have reported the synergistic effect of CB and nanoclay (NC) in natural rubber (NR). It has been demonstrated that the hybrid filler greatly improved the tensile strength by up to $147 \%$ as compared to the neat NR resulting from a formation of $\mathrm{CB} / \mathrm{NC}$ local filler network. However, the elongation at break decreased as the synergistic effects of the $\mathrm{CB} / \mathrm{NC}$ hybrid filler limited the slippage of the molecular chains along the filler surface. The reinforcement mechanism of hybrid CB/NC in NR was further investigated by Liu and co-workers [21]. Based on rheological studies, they suggested that hydrodynamic effect and chemical crosslink density were less important in determining the reinforcement effect of NR filled with the hybrid filler, since synergistic reinforcement effect of hybrid $\mathrm{CB} /$ organoclay(OC) becomes more dominant due to the strong physical interaction of the dual filler networking. In another study, Zhao and colleagues [22] reported that the synergistic effect of sodium stearate nanobarite ( $\mathrm{SA}-\mathrm{Al}_{2}-$ $\mathrm{O}_{3}-\mathrm{NB}$ )/CB hybrid filler had accelerated the curing process, improved mechanical properties, enhanced thermo-oxidative and corrosion resistance of NR vulcanizates when an optimum $\mathrm{SA}-\mathrm{Al}_{2}-\mathrm{O}_{3}-\mathrm{NB} / \mathrm{CB}$ ratio of $45 / 2$ was reached.

Therefore, based on the work reported previously, it has been found that the NR and SBR vulcanizates filled with hybrid fillers gained much improvement in properties due to the synergistic reinforcement of these fillers. However, up to date not much effort has been devoted to investigating the effect of hybrid reinforcement in non-hydrocarbon elastomers such as silicone rubber (SR). SR is a class of speciality rubber which is 
suitable for an extensive range of applications due to its ability to maintain good resistance to radiation, ozone and chemicals, excellent electrical properties, physiological inertness, low surface tension and compression set resistance at low temperatures below $40{ }^{\circ} \mathrm{C}$ and at high temperatures above $150{ }^{\circ} \mathrm{C}$. However, the major drawback of this elastomer is its poor mechanical strength. Fumed silica (FS) is used exclusively in SR to improve its tensile properties, tear strength, modulus and hardness. It has been demonstrated that strong polymer-filler interface resulting from chemical interactions between silanol groups ( $\mathrm{Si}-\mathrm{OH})$ on the silica surface and siloxane (Si-O-Si) in the SR backbone are responsible for the improvement in the mechanical properties of silica-filled SR [23-25]. However, fumed silica is an expensive filler and therefore it incurs high cost to the SR-based products.

Jia and co-workers [26] carried out an investigation into the effect of partial replacement of FS filler in SR filled with organoclay montmorillonite(OMMT)/FS hybrid filler. In their study, the mechanical and barrier properties were compared between SR/OMMT/FS (100 phr/30 phr/20 phr) ternary nanocomposites and SR/OMMT (100 $\mathrm{phr} / 30 \mathrm{phr}$ ) binary nanocomposite. It was found that the ternary nanocomposites displayed better mechanical properties and also decreased permeability coefficient by about $60 \%$, indicating better gas barrier properties. The inclusion of FS in the rubber before mixing OMMT increased the viscosity of the compound and mechanical shearing 
force during mixing with OMMT. As a result, the ternary nanocomposites exhibited better dispersion of OMMT in the rubber matrix.

In a recent study, we exfoliated 6 phr pure MMT (Cloisite $\mathrm{Na}^{+}$) in SR without any treatment or modification [27]. In view of the encouraging results reported for the synergistic effects of some hybrid filler systems containing silica [19-22], a hybrid filler system based on MMT and precipitated amorphous white silica filler (PS) was prepared and mixed with SR. Both MMT and PS fillers are non-petroleum based which are safe to handle and known to be environmental-friendly materials. In addition, these fillers are relatively cheap compared with FS, thus it helps to reduce the current processing cost and increase the economic benefit to the rubber manufacturing industry.

The amount of PS was increased from 0 to 10 phr whilst the amount of MMT was kept constant at $6 \mathrm{phr}$ in the hybrid filler weight ratio. The idea was to investigate synergistic effects of this hybrid filler system if any on the rubber properties. To the best of our knowledge, no work has been reported to date on the effect of this hybrid filler system on the properties of SR. The effect of increasing the hybrid filler weight ratio from 0.4 to 1.7 on the tensile strength, modulus at $100 \%$ and 300\% elongation (M100 and M300), elongation at break, Young's modulus, stored energy density at break, hardness and hysteresis of the nanocomposite was investigated. The properties of the SR/PS/MMT nanocomposite were then compared with those containing MMT and PS fillers as well as 
the control rubber. The advantages of the hybrid filler to the properties of the rubber vulcanizate were discussed in this paper.

\section{EXPERIMENTAL}

\section{Materials}

The raw elastomer used was polydimethyl siloxane Silastic (R) SGM-26 with a molecular weight of 300,000. Silastic SGM-26 is a random copolymer in which some of the methyl groups were substituted with vinyl ones producing vinyl dimethyl silicone rubber. The end groups were vinyl siloxane. The vinyl content was $0.12 \mathrm{wt} \%$ (Dow Corning Limited, UK). A high purity (99 \%) bis (alpha,alpha-dimethylbenzyl) peroxide known also as dicumyl peroxide (DCP) was used as a vulcanizing agent (Fisher Scientific, UK). The reinforcing nanofillers were precipitated amorphous white silicatype Ultrasil VN3 provided by Evonik Industries AG of Germany and Cloisite $\mathrm{Na}^{+}$ (Montmorillonite, MMT) clay supplied by Southern Clay, USA. Ultrasil VN3 has a 175 $\mathrm{m}^{2} / \mathrm{g}$ surface area (measured by $\mathrm{N}_{2}$ adsorption) and a 20-54 nm particle size.

Preparation of silicone rubber (SR) nanocomposites

Six SR nanocomposites were made with PS and MMT fillers. An unfilled rubber was also prepared as control compound by mixing the raw rubber with 0.3 phr DCP. A previous investigation showed that $0.3 \mathrm{phr}$ DCP was sufficient to fully cure the silicone rubber [28] and this amount was subsequently used to make the rubber compounds for 
this study. Prior to mixing, the clay was dried in a vacuum oven at $60{ }^{\circ} \mathrm{C}$ for 48 hours to remove moisture. The SR and all the compounding ingredients were then mixed in a Polylab mixer Haake Rheocord internal mixer (ThermoHAAKE, Germany), using counter-rotating Banbury rotors. The temperature of the mixing chamber and the rotor speed were set at $20^{\circ} \mathrm{C}$ and 50 r.p.m., respectively, and the total mixing time was 15 minutes. To make the control rubber, peroxide was added to the raw rubber and mixed for 15 min. The SR/PS and SR/MMT nanocomposites were prepared by mixing the raw rubber with the PS and MMT fillers for 10 min after which peroxide was added and mixed for another 5 min. The SR/PS/MMT nanocomposites were made by mixing the raw rubber with MMT for 5 min and then PS was incorporated in the rubber and mixed for an additional $5 \mathrm{~min}$. Finally, peroxide was added and mixed for another $5 \mathrm{~min}$. Note that in a recent study we discovered that 6 phr MMT did not exfoliate in SR during meltmixing and only exfoliated when the rubber was cured at a high temperature, i.e. $160^{\circ} \mathrm{C}$ [27]. When the mixing parameters such as mixing time and mixing sequence were changed, these did not exfoliate the MMT filler in the rubber [27]. Therefore, the different mixing cycles used to prepare the nanocomposites for this study were selected because they were more suitable for preparing the rubber compounds.

An oscillating disc rheometer (ODR) (Monsanto, Swindon, UK) was used to measure the cure properties of the rubber compounds at $160{ }^{\circ} \mathrm{C}$ and an angular displacement of $\pm 3^{\circ}$ and test frequency of $1.7 \mathrm{~Hz}$ according to BS 1673; Part 10 (1977). 
The cure rate index (CRI), which is a measure of the rate of cure in the rubber, was calculated using cure traces of the rubber compounds and equation 1 from BS 903:Part A60:Section 60.1.

$$
\mathrm{CRI}=100 /\left(\mathrm{t}_{95}-\mathrm{ts}_{2}\right)
$$

where ts2 (scorch time) is the onset of cure and $t_{95}$ (optimum cure time) is the completion of cure. The rubber compounds were cured in a compression mould at $160{ }^{\circ} \mathrm{C}$ in a 40 ton hydraulic press to produce sheets $150 \mathrm{~mm}$ by $150 \mathrm{~mm}$ in dimensions and approximately $2 \mathrm{~mm}$ thick. To avoid anisotropy from forming in the rubber sheets, the rubber compound was placed in the centre of the mould to allow it to flow in all directions before cure started. The formulations of the rubber compounds are listed in Table 1.

Measurement of the clay dispersion in the nanocomposites

The X-ray diffraction (XRD) spectra of the layered silicates and clay-filled nanocomposites were produced on a Bruker D8 diffractometer (Bruker, Germany). The diffractometer was equipped with $\mathrm{Cu} K \alpha$ radiation $(\lambda=0.15418 \mathrm{~nm}), 40 \mathrm{~mA}$ of current and $40 \mathrm{kV}$ of voltage. A minimum of $3 \mathrm{~g}$ of dried clay powder was used to carry out the X-ray analysis of the mineral clay. A square flat sheet $30 \mathrm{~mm}$ by $30 \mathrm{~mm}$ in dimensions and $2 \mathrm{~mm}$ thick of the cured compound was required for the X-ray analysis of the SR nanocomposites. The experiment was performed at a low angle in the range $2 \theta=1-10^{\circ}$ 
with the scan rate of $0.02 \%$. In addition, the spacing between the structural layers of the silicates was measured according to the Bragg's law

$$
\lambda \mathrm{n}=2 \mathrm{~d} \sin \theta
$$

where $n$ is an integer, $\lambda$ is the X-ray wavelength, $d$ is the interlayer spacing, and $\theta$ is the angle of diffraction.

Determination of PS and MMT and PS/MMT hybrid fillers dispersion in the rubber

Dispersion of the PS, MMT, and hybrid fillers in the rubber was assessed by a Carl Zeis Leo 1530VP Field Emission Gun Scanning Electron Microscope (FEGSEM) (Carl Zeiss NTS GmbH, Oberkochen, Germany). Small pieces of the cured rubber were placed in liquid nitrogen for $3 \mathrm{~min}$ and then fractured to create two fresh surfaces. The samples, $65 \mathrm{~mm}^{2}$ in area and $2 \mathrm{~mm}$ thick, were coated with gold and then examined and photographed in the FEGSEM. The degree of dispersion of the PS, MMT and hybrid fillers in the rubber was then examined at 5000x and $10000 \mathrm{x}$ magnifications, respectively.

Determination of the mechanical and stress-strain properties of the nanocomposites

The tensile stress, elongation at break, Young's modulus, modulus at $100 \%$ (M100) and 300\% elongation (M300) and stored energy density at break of the nanocomposites were measured in uniaxial tension in a Lloyd testing machine LR50K (Hampshire, UK) with standard dumbbell test pieces at $24{ }^{\circ} \mathrm{C}$ and a cross-head speed of $100 \mathrm{~mm} / \mathrm{min}$ according to BS 903: Part A2;1995. Lloyd Nexygen 4.5.1 computer 
software was used to store and process the data. Five test pieces were tested for each compound and the median of the values was subsequently noted. Standard deviation for all the mechanical properties were subsequently calculated and added to the results.

The elongation of the rubber test pieces was set at $200 \%$ and $400 \%$, which corresponded to 50 and $100 \mathrm{~mm}$ extension of the original gauge length of the standard dumbbell test pieces, respectively. The energy dissipated in the rubber was calculated from the hysteresis loop, which was the area between the extension and retraction curves in each cycle. In each test, 10 stress-strain curves were generated at $100 \mathrm{~mm} / \mathrm{min}$ crosshead speed. The hardness was measured in a Shore A Durometer hardness tester (The Shore Instrument and MFG, Co., New York) at $24{ }^{\circ} \mathrm{C}$ according to BS903: Part A26; 1995. Finally, the median of the hardness values was noted.

\section{RESULTS AND DISCUSSIONS}

Fillers dispersion in the SR/MMT, SR/PS and SR/PS/MMT nanocomposites

Fig. 1 compares the XRD spectra of the pure clay and SR/MMT nanocomposite containing $6 \mathrm{phr}$ MMT. The pure clay showed a distinct diffraction peak at $2 \theta=7.23^{\circ}$. According to Bragg's law, the distance of basal spacing ( $\left.\mathrm{d}_{001}\right)$ was $1.22 \mathrm{~nm}$. As can be seen, a flat curve was observed for the SR/MMT nanocomposite. The absence of a peak on the spectrum suggested that a highly exfoliated morphology was achieved in the matrix of the rubber. 
As reported in various studies [29-31], exfoliated microstructure is referred to when stacked layers in the clay structure separate into single platelets. Consequently, only a silent peak appeared in the XRD spectrum (Fig. 1) because the X-ray scan could not measure the wide spacing between the stacked layers of clay when exfoliation took place. This was because no diffraction signal could be detected when the $d$ spacing of the clay was greater than $8 \mathrm{~nm}$ or reached the X-ray scattering detection limit [29]. Therefore, based on the XRD analysis, it was concluded that the SR/MMT nanocomposite filled with 6 phr MMT contained highly exfoliated clay platelets.

The XRD spectra of the pure clay and SR/PS/MMT nanocomposites with the hybrid filler weight ratios of 0.4 and 1.7 are shown in Fig. 2. The spectra of the SR/PS/MMT nanocomposites exhibited distinct diffraction peaks at $2 \theta=7.4^{\circ}$ and $2 \theta=7.5^{\circ}$ (Fig. 2c and 2d), which according to Bragg's law correspond to $1.20 \mathrm{~nm}$ and $1.18 \mathrm{~nm}$ distance of basal spacing $\left(\mathrm{d}_{001}\right)$, respectively. These values were close to the $d$ spacing of the pure clay which was $1.22 \mathrm{~nm}$ (Fig. 2a). Recall that MMT particles were exfoliated in the SR/MMT nanocomposite (Fig. 2b). Evidently, the inclusion of PS prevented the MMT particles from exfoliating in the rubber.

The SEM micrographs in Figs. 3(a-e) show dispersion of the MMT and PS fillers in the SR/PS, SR/MMT and SR/PS/MMT nanocomposites at low magnification (5000x) and high magnification (10,000x), respectively. Figs. 3a (i-ii) represents the overall MMT dispersion in the rubber matrix. Only a few filler aggregates were seen in the rubber and 
the aggregate size was roughly $1 \mu \mathrm{m}$ in size (Fig. 3a (ii)). The result also indicated that good dispersion of the MMT particles in the rubber matrix was achieved. Similarly, the XRD analysis (Fig. 1) showed highly exfoliated MMT in the nanocomposite.

Figs. 3b \& 3c, illustrated that most of the PS particles dispersed well in the rubber matrix even at high filler concentrations such as 10 phr (Figs. 3c (i-ii)). Only a few large aggregates roughly $3 \mu \mathrm{m}$ in size were seen and this was caused by the strong interaction between the PS particles. Normally, the silica surface is treated with bifunctional organosilane to reduce filler-filler interaction and increase dipersibility of the filler particles in rubber [32]. Since no silane was used in this study, filler aggregates were expected to form in the rubber matrix.

Figs. 3d (i-ii) show MMT and PS fillers dispersed in the SR/PS/MMT nanocomposite with the hybrid filler weight ratio of 0.4. It was noticed that the MMT (bright dots with platy shape) and the PS (bright dots with round shape) particles were separately dispersed in the matrix (Fig. 3d (i)). This suggested that there was no PS-MMT network in the nanocomposites. In addition, Fig. 3d (ii) showed that MMT particles failed to exfoliate in the rubber matrix and formed aggregates roughly $3 \mu \mathrm{m}$ in size. This was also supported by the XRD analysis (Fig. 2). However, there was little evidence of the PS aggregates in the SR/PS/MMT nanocomposite with the hybrid filler weight ratio of 0.4 , probably because there was small amount of the PS filler in the rubber. 
Figs. 3e (i-ii) show the dispersion of the SR/PS/MMT nanocomposite with filler weight ratio of 1.7. Obviously, the rubber matrix contained a lot of PS particles as well as aggregates, which were up to $2 \mu \mathrm{m}$ in size. Remember that no silane treatment was applied to the silica surface to prevent the PS particles from agglomerating due to high filler-filler interaction. Similar to the nanocomposite with the low hybrid filler weight ratio of 0.4 , most of the MMT particles (bright platy shape) formed aggregates in the range of sub-micron particle size. This suggested that no exfoliation of MMT occurred in the rubber matrix. Both PS and MMT fillers were dispersed separately in the rubber matrix and this indicated that there was no internal network formed between the two.

Dispersion of the organically modified montmorillonites (OMMT) in rubber matrix depends on two factors. The viscosity of the nanocomposite increases with silica loading increasing. This facilitates transferring mechanical shearing force to OMMT particles, resulting in better dispersion of the OMMT particles in the SR matrix [26]. Clearly, this did not happen here. And secondly, the OMMT distribution in the rubber matrix is a dynamic equilibrium process, which means that the dispersion and reagglomeration of OMMT particles happen simultaneously [26]. This might have occurred in the SR/PS/MMT nanocomposites. Note that the minimum torque $\mathrm{M}_{\mathrm{L}}$ is a measure of rubber viscosity and is affected by structure and polymer-filler interaction [33]. $\mathrm{M}_{\mathrm{L}}$ increased progressively when the PS loading in the PS/MMT hybrid filler system was raised to 10 phr (Table 2). This viscosity increase was relatively low and did not provide 
sufficient mechanical shearing force to disperse the MMT particles well in the rubber [26]. This resulted in the re-agglomeration of the MMT particles in the rubber matrix.

Cure characteristics of the control SR, SR/MMT, SR/PS and SR/PS/MMT nanocomposites.

Table 2 presents the results from the cure tests. These include optimum cure time $\left(t_{95}\right)$, scorch time $\left(t_{\mathrm{s} 2}\right)$, minimum torque $\left(M_{L}\right)$, maximum torque $\left(M_{H}\right)$ and $\Delta$ torque $(\Delta \mathrm{M})$ of the control rubber, SR/MMT nanocomposite containing $6 \mathrm{phr}$ MMT, SR/PS nanocomposites containing 6 and 10 phr PS, and the SR/PS/MMT nanocomposite where the hybrid filler weight ratio was increased from 0.4 to 1.7. Overall, the optimum cure time of the SR/PS/MMT nanocomposite was longer than that of the SR/MMT nanocomposite, irrespective of the hybrid filler weight ratio. The scorch time of the nanocomposites were fairly similar at about 3 min with the exception of the SR/PS nanocomposite with $10 \mathrm{phr}$ PS and SR/PS/MMT nanocomposite with the hybrid filler weight ratio of 1.7, which had similar scorch times at 2.5 min. The minimum torque, which indicated rubber viscosity, rose by $70 \%$ when the optimum loading of the hybrid filler weight ratio was reached. This was expected because solid fillers increase rubber viscosity. Also, for these nanocomposites, the maximum torque rose by $33 \%$ and $\Delta$ torque by 30\%, respectively . (cf. SR/MMT (MMT: 6 phr) and SR/PS/MMT (PS/MMT: 1.7)). 
As stated earlier, $\Delta$ torque indicates crosslink density changes in the rubber and on this basis, the addition of the hybrid filler was beneficial to the crosslink density of the rubber. Note also that the $\Delta$ torque of the SR/PS nanocomposite increased by approximately $12 \%$ when the PS loading was raised from 6 to 10 phr. A study demonstrated that when the silica loading was increased, the filler particles tended to interact between themselves due to high surface area and abundance of the $\mathrm{OH}$ groups on the silica surface. As a result, the viscosity of the compound increased due to high silicasilica interaction [24, 25]. Furthermore, hydrogen bonds were formed between the oxygen atoms in the SR backbone and the silanol groups on the silica surface and this acted as additional crosslinks in the rubber and larger $\Delta$ torque values were recorded. It was particularly interesting to note that the crosslink density benefitted so much from the rise in the hybrid filler weight ratio in the rubber as shown by a noticeable improvement in the $\Delta$ torque values. Evidently, the addition and progressive increase in the loading of PS in the SR/PS/MMT nanocomposite was beneficial to the crosslink density and mechanical properties of the nanocomposite.

For the purpose of clarity, the cure traces of the control rubber, SR/MMT, SR/PS, and SR/PS/MMT nanocomposites with the hybrid filler weight ratios of $0.4,1.0$ and 1.7 were compared in Fig. 4. It was obvious that some of the cure properties of the SR/PS/MMT nanocomposites were significantly better than those of the control rubber. For example, $\Delta$ torque was $43 \%$ higher for the SR/PS/MMT nanocomposite containing 
the hybrid filler weight ratio of 1.7. However, the optimum cure time and the rate of cure were adversely affected by the addition of the hybrid filler. The optimum cure time increased by $85 \%$ and the cure rate index decreased by $63 \%$ when the hybrid filler weight ratio reached 1.7 ((cf. SR/PS/MMT (PS/MMT:1.7) and control SR). Note that the SR/MMT nanocomposite with 6 phr MMT had similar optimum cure and scorch times to the control rubber but a higher $\Delta$ torque value. However, the SR/PS nanocomposite with 6 phr PS had a longer optimum cure time compared with the control rubber though the scorch times were similar. The $\Delta$ torque of the SR/PS nanocomposite with 6 phr PS was roughly $20 \%$ higher than that of the control rubber, which indicated a higher crosslink density. It was noted that the cure rate index of the SR/PS nanocomposite with 6 phr PS was $50 \%$ lower than that of the SR/MMT nanocomposite with 6 phr MMT, which indicated a lower crosslink density in the rubber. Adverse effects of an increasing loading of PS on the cure time and rate of cure of a DCP-cured SR have been reported [28].

During high temperature cure, DCP decomposes to generate free radicals when heated. A hydrogen atom is abstracted from the methyl group leaving a methyl free radical attached to silicon. In the case of vinyl group, the free radical adds to the vinyl group. Crosslinks are subsequently formed in these particular reactions [34]. The increase in mechanical properties such as tensile strength of SR is mainly due to strong polymer-filler bonding and filler structure. The filler surface energy is a deciding factor in the nature of the bonding forces which includes accessibility of the silica silanol 
groups. In the case of hydrophilic silica surface, the bonding is related predominantly to physical forces such as van der Waals forces and hydrogen bonding but covalent bonding upon vulcanization can not be excluded [35]. Note that the PS in the hybrid filler system was untreated and hydrophilic by nature.

The crosslink density of the SR/PS/MMT nanocomposite as indicated by the $\Delta$ torque values increased by almost $30 \%$ when the loading of PS in the hybrid filler weight ratio reached 1.7. This was in comparison with the $\Delta$ torque values measured for the SR/MMT nanocomposite with $6 \mathrm{phr}$ MMT. This was due to the formation of physical bonds between the rubber chains and PS. The optimum cure time increased and rate of cure as shown by the cure rate index decreased (Table 2). The former indicated that physical bonding and possibly covalent bonding between PS and the rubber chains took longer to complete than the DCP curing of the rubber, and the latter implied that the rate at which this occurred was much slower than that of the DCP curing. It must also be noted that curatives are known to adsorb on the surface of silica, which excludes them from reacting with rubber chains during curing to form crosslinks [36]. This is exasperated when the loading of silica is increased and explains the adverse effect of the PS filler on the cure properties of the nanocomposites. The scorch time was slightly shorter for the SR/PS/MMT nanocomposite with the hybrid filler weight ratio of 1.7. when compared with that of the SR/MMT nanocomposite. Recall also that these compounds had the same loading of DCP. 
Effect of the PS/MMT hybrid filler weight ratio on the mechanical properties of the SR/PS/MMT nanocomposite

The properties of the control rubber were: tensile strength, $0.40 \mathrm{MPa}$; Young's modulus, 0.30 MPa; M100, 0.20 MPa; M300, 0.30 MPa; elongation at break, 756\%; stored energy density at break, $2.42 \mathrm{~mJ} / \mathrm{m}^{3}$; hardness 18.5 Shore A. Figs. 5(a-f) present the tensile strength, Young's modulus, M100, elongation at break, stored energy density at break and hardness of the SR/PS/MMT nanocomposites as a function of the hybrid filler weight ratio, respectively. Overall, the tensile strength increased by $178 \%$ (Fig. 5a), Young's modulus by 79\% (Fig. 5b), M100 by 33\% (Fig. 5c), elongation at break by $49 \%$ (Fig. 5d) and stored energy density at break by 202\% (Fig. 5e) as the hybrid filler weight ratio was increased from 0 to 1.7.

From the results, it was clear that improvement in both the tensile strength and modulus was achieved without causing a detrimental effect on the elongation at break of the rubber. In addition, the stored energy density at break is a measure of the energy stored per unit volume in the rubber before the sample finally breaks, hence it was concluded that the increase in the hybrid filler weight ratio enhanced resistance to crack initiation and crack growth in the rubber. The rubber properties such as tensile strength and stored energy density at break depend on crosslink density $[37,38]$. Since the MMT particles did not exfoliate in the SR/PS/MMT nanocomposites to provide optimum reinforcement for the rubber hence the improvement seen in the tensile properties was 
mainly due to the interaction between the active sites on the PS surface and the SR chains which provided additional crosslinks between the SR chains and PS [39].

The hardness benefitted from increases in the hybrid filler weight ratio to 1.7, and rose by 35\% (Fig. 5f). The rise in the hardness was consistent with the increases recorded for the Young's modulus, M100 and M300. This provided additional evidence of the increase of crosslink density in the rubber. In the case of the SR/MMT nanocomposite, when MMT exfoliated the rubber properties improved significantly. For example, the tensile strength increased by 73\%, Young's modulus by 30\%, stored energy density at break by $34 \%$, and hardness by $8 \%$ in comparison with the control rubber. Though, the elongation at break remained almost unchanged (Table 3).

The mechanical properties of the SR/PS/MMT nanocomposites were marginally better than those of the SR/PS and SR/MMT nanocomposites with 6 phr PS and 6 phr MMT, respectively (Table 3). For example, the tensile strength of the SR/PS/MMT with the hybrid filler weight ratio of 1.7 was $67 \%$ and $178 \%$ higher than those of the SR/PS and SR/MMT nanocomposites, respectively. A similar trend was also observed for the remaining properties. It was noted that the margin became smaller when the loading of PS in the SR/PS nanocomposites was increased to 10 phr. Probably the most interesting results were recorded for the stored energy density at break. This property for the SR/PS/MMT nanocomposite with the hybrid filler weight ratio of 1.7 was $96 \%$ and 203\% higher than those calculated for the SR/PS and SR/MMT nanocomposites with 6 phr PS 
and 6 phr MMT fillers, respectively. This was a major improvement in the fracture property of the nanocomposite because of the hybrid filler.

Effect of PS/MMT hybrid filler on the stress-strain behaviour of the nanocomposites

Fig. 6a presents stress-strain curves of the control rubber, SR/MMT with 6 phr MMT and SR/PS nanocomposites containing $6 \mathrm{phr}$ and $10 \mathrm{phr}$ PS. The stress-strain properties of the rubber improved substantially when MMT and PS fillers were added. Interestingly, when the stress-strain properties of the nanocomposites with the same amount of PS and MMT, i.e $6 \mathrm{phr}$, were compared with that of the control rubber, the nancomposite with PS had superior properties. In this case, the maximum stress was $67 \%$ higher in favour of the rubber with the PS filler (cf. Fig. 6(i) with Fig. 6a(ii) and Fig. 6a(iii)) and it continued improving up to $194 \%$ when the PS loading was increased to 10 phr (Fig 6a(iv)). This was due to the additional hydrogen bonding in the SR/PS nanocomposite which stiffened up the rubber [39].

The inclusion of the hybrid filler in the rubber showed a similar effect. The maximum stress recorded for the SR/PS/MMT nanocomposite with the hybrid filler weight ratio of 0.4 showed a $98 \%$ improvement compared with the control rubber (cf. (Fig. 6b (i) and Fig. 6b(ii)). As the hybrid filler weight ratio was raised to 1.7, the maximum stress was $308 \%$ higher than that of the control rubber (cf. Fig. 6b (i) and Fig. 6b(iv)). Clearly, the hybrid filler was very beneficial to the stress-strain properties of the 
rubber. Interestingly, the stress-strain curves of the SR/PS/MMT nanocomposite exhibited a large increase in the stress level at higher deformation as shown in Fig. 6b (iv). Normally, this phenomenon is seen in filled NR compounds because the hydrocarbon chains crystallize on stretching at high strains, increasing the strength of the rubber. However, for non-crystallising rubbers such as SR this behaviour does not occur. It was believed that the high surface activity of PS was beneficial to the higher stress level recorded for the SR/PS/MMT nanocomposite. Although, MMT did not exfoliate in the rubber, some contribution from this filler to the rubber properties could not be ruled out. Therefore, it was concluded that the improvement in the stress-strain properties of the SR/PS/MMT nanocomposite was mainly due to the contribution from the individual filler rather than a synergistic effect of the hybrid filler.

Hysteresis in the control rubber, SR/PS, SR/MMT and SR/PS/MMT nanocomposites

When rubber is deformed, it stores energy but because it is a visco-elastic material, some of the energy is dissipated as heat in the rubber and this is termed hysteresis. Generally, the inclusion of solid fillers such as PS and MMT cause energy dissipation or hysteresis in rubber. Hysteresis is measured from the area under a stressstrain graph which is produced in a single cycle. In order to measure hysteresis in the rubbers, standard dumbbell test pieces were cycled repeatedly up to 10 cycles at $200 \%$ and $400 \%$ elongation to generate stress-strain traces. The energy loss or energy dissipation in the rubber was calculated from the area between the extension-retraction 
curves produced after the first cycle at $200 \%$ and $400 \%$ elongation. The results were summarised in Table 4. Typical stress-strain curves for the control rubber and nanocomposites with PS and MMT at 400\% strain amplitude are shown in Fig. 7a.

The energy loss of an unfilled cured rubber is entirely due to the frictional movement of the rubber chains, whereas in the nanocomposites, there are a few additional factors that cause hysteresis. These are filler-filler interaction [40], rubberfiller interaction [41], detachment from the filler surface or slippage on the filler surface of chains having reached their limit of extensibility [42-44], as well as frictional movement of the rubber chains. When untreated PS is added to rubber, the PS particles do not disperse well in the rubber matrix and filler aggregates are formed because of high surface energy of PS. At the same time, PS can interact with the rubber chains though to a lesser extent than well dispersed PS particles do, to form hydrogen bonds. Hydrogen bonds increase the rubber stiffness and modulus [45]. The filler network is composed of hard regions, where high volume fraction of filler exists, and soft regions, where low volume fraction of filler is present. Hard regions convert into soft regions when stress is applied to the rubber and as a result this mechanism will generate energy loss [46].

In the case of rubber-filler interactions, there are two kinds of interactions namely weak Van der Waals bonds resulting from physical adsorption of rubber chains on the filler surface, and strong links which cannot be broken during deformation [47]. Rubber chains which are attached between filler particles break or detach under strain [46]. In 
fact, filler aggregates are bound together by a distribution of chains of different lengths. The shortest chains will reach their limit of extensibility and then break when rubber is deformed. There is also chain slippage process onto the filler surface [48,49].

As can be seen in Table 4, both SR/MMT and SR/PS nancomposites exhibited higher energy loses than the control rubber at both elongations. This was because in the filled rubbers, the level of energy loss was influenced by the dispersion of the fillers. At $200 \%$ strain amplitude, the energy loss increased by 38\% and 8\%, respectively when $6 \mathrm{phr}$ MMT and 6 phr PS were added. A similar trend was also observed at $400 \%$ strain amplitude, where energy loss was at $43 \%$ and $8 \%$, respectively for the two nanocomposites. The results clearly showed that the inclusion of MMT contributed to more energy loss in the rubber than the silica did. There are at least three possible mechanisms to explain the energy loss in these nanocomposites. Recall that in the SR/MMT nancomposite most of the MMT particles were exfoliated, creating platelets in the rubber matrix (Figs $1 \&$ 3a). The rubber chains physically adsorbed on the surface of the platelets by weak attractive Van der Waals forces and when the rubber was deformed, the chains detached from the platelets. There was also energy loss due to the internal friction between the macromolecular chains. Ideally, in a filled rubber low hysteresis will be realized if interaction between filler particles and rubber chains is strong. Since the physical interaction between the platelets and rubber chains was not strong enough to 
restrict the chain mobility too much, the chains detached and slid over each other, causing energy dissipation in the rubber.

On the other hand, in the SR/PS nanocomposite, hydrogen bonds formed between the oxygen atoms in the SR backbone and the silanol groups on the PS surface, which led to strong links between the two and thus there was less frictional movement and energy dissipation within the rubber during the deformation process. Also, as Figs. 3b \& 3c show, the filler network was composed of hard regions and soft regions. The hard regions converted into soft regions when stress was applied to the rubber. It is also likely that the rubber chains which were attached between the filler particles broke or detached under strain and this contributed to the energy loss in both nanocomposites. When the loading of PS was raised to $10 \mathrm{phr}$, the energy loss was 58\% higher than that of the control rubber and $46 \%$ higher than that of the SR/PS nanocomposite with 6 phr PS at $200 \%$ strain. When the loading of PS was raised to $10 \mathrm{phr}$, this produced more hard regions which converted into soft regions, more detachment from the filler surface or slippage on the filler surface of chains having reached their limit of extensibility, as well as frictional movement of the rubber chains. Moreover, more PS meant a higher concentration of the OH groups on the silica surface which produced stronger links with the rubber chains and therefore the PS-rubber interaction became even more dominant. This in turn should have reduced the energy loss in the SR/PS nanocomposite but it did not. This suggested that 
the other processes described above were more effective in increasing the energy loss in the nanocomposite.

Typical stress-strain traces for the control rubber and nanocomposites with PS, MMT and hybrid filler at 400\% strain amplitude are shown in Figs. 7a-7b. Overall, the energy loss of the SR/PS/MMT nancomposites increased as the hybrid filler weight ratio was raised as indicated by the size of the hysteresis loops (Fig. 7b). The SR/PS/MMT nanocomposite with the hybrid filler weight ratio of 0.4 possessed an energy loss of 123 $\mathrm{mJ} / \mathrm{m}^{3}$ and for the SR/PS/MMT nanocomposite with the hybrid filler weight ratio of 1.7 , the energy loss was $275 \mathrm{~mJ} / \mathrm{m}^{3}$, respectively. As mentioned earlier, MMT did not exfoliate in the SR/PS/MMT nanocomposites to produce platelets and hence there was little physical interaction between MMT and the rubber chains. It was concluded that the large increase in the energy loss as a function of the hybrid filler weight ratio was mainly due to PS with little contribution from MMT. On this basis, five mechanisms may be envisaged to have caused the energy loss in this nanocomposite: filler-filler interaction, rubber-filler interaction, detachment from the filler surface or slippage on the filler surface of chains having reached their limit of extensibility, breaking up of chains binding the filler particles together as well as frictional movement of the rubber chains [44-49].

Since the untreated silica produced strong interaction with the silicone rubber chains and a greater number of links, it was assumed that there was strong PS-rubber 
interaction and little detachment from the PS surface or slippage on the PS surface of chains having reached their limit of extensibility. Therefore, the large energy loss measured for the SR/PS/MMT nancomposites was due to PS-PS interaction, which lead to the formation of hard regions which converted to soft regions (Figs. 3d \& 3e), breaking up of short rubber chains binding the PS particles together, and frictional movement of the rubber chains. These processes were exasperated when the PS loading was increased progressively in the hybrid filler system. Obviously, the hybrid filler weight ratio was an important factor in controlling the energy loss in the nanocomposites. Moreover, the energy loss depended strongly on the interaction of the PS and MMT fillers with the SR chains as well as the dispersion of the fillers in the rubber matrix. Finally, there was no evidence of a synergistic effect of the MMT and PS fillers on the rubber properties under the present mixing and curing conditions.

\section{CONCLUSION}

From this study, it was concluded that

1- By increasing the hybrid filler weight ratio, the tensile strength, Young's modulus, M100, M300, elongation at break, stored energy density at break and hardness of the SR/PS/MMT nanocomposite improved compared with those of the control rubber, and SR/PS and SR/MMT nanocomposites. 
2 - The stress-strain properties of the nanocomposites with the hybrid filler showed a large improvement at high deformation in comparison with those containing the PS and MMT fillers. The MMT filler exfoliated in the SR/MMT nanocomposite but did not in the nanocomposite containing the hybrid filler. Therefore, PS was detrimental to the MMT dispersion in the rubber. As expected, the untreated PS formed aggregates in the rubber matrix.

3 - The results showed a positive contribution to the crosslink density of the rubber from the hybrid filler, which was caused by the PS-rubber network formation in the rubber. There was no evidence of a synergistic effect of the hybrid filler on the rubber properties. The rate of cure retarded when the hybrid filler weight ratio was raised in the rubber. This indicated that the hybrid filler slowed down the rate of the peroxide curing reaction in the rubber.

4 - The energy loss in the SR/PS/MMT nanocomposite increased as the hybrid filler weight ratio was raised from 0.4 to 1.7. A similar effect was recorded for the nanocomposites containing $6 \mathrm{phr}$ PS and $6 \mathrm{phr}$ MMT fillers though the energy loss in these rubbers was not as high as that measured for the SR/PS/MMT nanocomposites.

\section{ACKNOWLEDGEMENT}

We are grateful to the Malaysian Rubber Board for funding this project. We also thank the Loughborough Materials Characterisation Centre for their technical assistance. 


\section{REFERENCES}

1. P. Li, L. Wang, G. Song, L. Yin, F. Qi, and L. Sun, J. Appl. Polym. Sci., 109, 3831 (2008).

2. P. L. Teh, Z. A. Mohd Ishak, A. S. Hashim, J. Karger-Kocsis, and U. S. Ishiaku, J. Appl. Polym. Sci., 100, 1083 (2006).

3. E. T. Thostenson, C. Li, and T. Chou, Comp. Sci. Tech., 65, 491 (2005).

4. $\quad$ S. Varghese, J. Karger-Kocsis, K. G. Gatos, Polymer, 44, 3977 (2003).

5. N. Rattanasom, S. Prasertsri, \& T. Ruangritnumchai, Polym. Test., 28, 8 (2009).

6. D. Jia, L. Liu, X. Wang, B. Guo, and Y. Luo, Advances in natural Rubber/Montmorillonite Nanocomposites: Biodegradable Polymer

Blends and Composites from Renewable Resources, New Jersey, 2008, pp. 415

7. T.P. Chua, M. Mariatti, A. Azizan and A.A. Rashid, Comp. Sci. Techol., 70, $671(2010)$.

8. R. Verdejo, C. Saiz-Arroyo, J. Carretero-Gonzalez, F. Barroso-Bujans, M. A. Rodriguez- Pereza and M. A. Lopez-Manchado, Eur. Polym. J., 44, 2790 (2008).

9. $\quad$ L. Bokobza, Polymer, 48, 4907 (2007).

10. R. Stephen and S. Thomas, Rubber nanocomposites: preparation, properties and applications, New Jersey, 2010, pp 407

11. A. Ansarifar, S. F. Shiah, and M. Bennett, Inter. J. of Adhesion and Adhes., 26, 
454 (2006).

12. Y. Chen, Z. Peng, L. X. Kong, M. F. Huang, and P. W. Li, Polym. Eng. Sci., 48, 1674 (2008).

13. Y. Zhan, J. K. Wu, H. S. Xia, N. Yan, G. X. Fei, G. P. Yuan, Macromol. Mater.

Eng., 296, 590 (2011).

14. J. P. Lewicki, J. J. Liggat and M. Patel. Polym. Degrad. Stabil., 94, 1548 (2009).

15. R. Sengupta, S. Chakraborty, S. Bandyopadhyay, S. Dasgupta, R. Mukhopadhyay, K. Auddy, and A. S. Deuri, Polym. Eng. Sci., 47, 1956 (2007).

16. J.K. Kim, K. Pal, and V. Sridhar, Recent Advances in Elastomeric Nanocomposites:Advanced structured materials, Verlag Berlin Heidelberg, 2011, pp 5

17. L. Bokobza, Macr. Mat. Eng., 289, 607 (2004).

18. A. Das, K.W. Stöckelhuber, R. Jurk and G. Heinrich, Macromol. Symp., 95, 291 (2010).

19. L. Bokobza, M. Rahmani, C. Belin, J.L Bruneel and N.E. El Bounia, J. Polym. Sci. B Polym. Phys., 46, 1939 (2008).

20. L. Qu, G. Huang, P. Zhang, Y. Nie, G. Weng, and J. Wu, Polym. Int., 59, 1397 (2010). 
21. Y. B. Liu, L. Li, and, Q. Wang, Plast. Rubb.Comp., 39, 370 (2010).

22. G. Zhao, L. Shi, D. Zhang, X. Feng, S. Yuan, and J. Zhuo, Mater. Des., 35, 847 (2012).

23. A. Sarkar, Rubber Technologist's Handbook, 2nd ed, United Kingdom, 2009, pp 393

24. M. I. Aranguren, E. Mora, and C. W. Macosko, J. Colloid Inter. Sci., 195, 329 (1997).

25. P. Levresse, D. L. Feke, and I. Manas-Zloczower, Polymer, 39, 3919 (1998).

26. C. Jia, L. Zhang, H. Zhang and Y. Lu, Polym. Comp, 32, 1245 (2011).

27. N. I. Nik Ismail, A. Ansarifar, M. Song. Polym Eng \& Sci.. http://onlinelibrary.wiley.com/doi/10.1002/pen.23255/pdf

28. A. Ansarifar and B. Y. Lim, J Rubb Res., 9, 140 (2006).

29. D. R. Paul and L. M. Robeson, Polymer, 49, 3187 (2008).

30. S. Sinha Ray and M. Okamoto, Progg. Polym. Sci, 28, 1539 (2003).

31. S.C. Tjong, Nanocrystalline Materials: Their Synthesis -Structure Property Relationships and Applications, United Kingdom, 2006, pp 324.

32. A. Ansarifar, F. Saeed, S. Ostad-Movahed, L. Wang, K. Ansar Yasin, and S. Hameed, J Adhes Sci and Technol., 27, 371 (2013).

33. B. Boonstra, H. Cochrane and E. Dannenberg, Rubber Chem. Technol., 48, 558 
(1975).

34. P. G. Bork and C. W. Roush, Vulcanisation of Elastomers, Chapter 11, G.

Alliger, I. J Sjouthun, Ed. Reinhold., Pub. Corp., (1964) New York, NY.

35. E. L. Warrick, O. R. Pierce, K. E. Polmanteer and J. C. Saam, Rubber Chem.

Technol., 52, 437 (1979).

36. H. Ismail and S. M. Shaari. Polym Testing., 29, 872 (2010).

37. G. M. Bristow and R. F. Tiller. Kautsch Gummi Kunstst, 23, 55 (1970).

38. S. Wolff, Rubb. Chem. Technol., 69, 325 (1996).

39. S. E. Shim and A. I. Isayev, Rheo. Act., 43, 127 (2004).

40. J. Frohlich, W. Niedermeier and H-D. Luginsland, Comp. Part A., 36, 449 (1994).

41. H. T. Ewe, S. Wolff, M. Haddeman, H. P. Grewetta, and M. J. Wang, Rubb. Chem. Technol., 66, 594 (1993).

42. E.M. Danmenberg, Trans.Ins. Rubber Ind., 42, T26 (1996).

43. B. Boonstra, Reinforcement of Elastomer, New York, 1965, pp 100

44. G. Kraus, C.W. Childers and K.W. Rollman, J. Appl. Polym. Sci., 10, 229 (1966).

45. F. Clement, L. Bokobza and L. Monnerie, Rubb. Chem. and Technol., 74, 847 (2001).

46. L. Mullins and N.R. Tobin, Rubb. Chem. Technol., 30, 555 (1957). 
47. A.F. Blanchard and D. Parkinson, Ind. Eng. Chem., 44, 799 (1952).

48. F. Bueche, J. Appl. Polym. Sci., 4, 107 (1960).

49. F. Bueche, J. Appl. Polym. Sci., 5, 271 (1961). 
TABLE 1: Formulations of the rubber compounds

\begin{tabular}{lcccc}
\hline \multicolumn{1}{c}{ Compound } & \multicolumn{2}{c}{ Formulation (phr) } \\
& SR & DCP & MMT & PS \\
\hline Control SR & 100 & 0.3 & - & - \\
SR/MMT (MMT:6 phr) & 100 & 0.3 & 6 & - \\
SR/PS (PS:6 phr) & 100 & 0.3 & - & 6 \\
SR/PS (PS: 10 phr) & 100 & 0.3 & - & 10 \\
SR/PS/MMT (PS/MMT: 0.4) & 100 & 0.3 & 6 & 2.5 \\
SR/PS/MMT (PS/MMT: 1.0) & 100 & 0.3 & 6 & 6 \\
SR/PS/MMT (PS/MMT: 1.7) & 100 & 0.3 & 6 & 10 \\
\hline
\end{tabular}


TABLE 2: The cure characteristics of the control rubber and nanocomposites

\begin{tabular}{|c|c|c|c|c|c|c|}
\hline Compound & $\begin{array}{l}\text { Cure time } \\
\left(\mathrm{t}_{95} / \mathrm{min}\right)\end{array}$ & $\begin{array}{l}\text { scorch time } \\
\left(\mathrm{t}_{\mathrm{s} 2} / \mathrm{min}\right)\end{array}$ & $\begin{array}{l}\text { CRI } \\
\left(\min ^{-1}\right)\end{array}$ & $\begin{array}{l}\text { Max torque } \\
\left(\mathrm{M}_{\mathrm{H}} / \mathrm{dNm}\right)\end{array}$ & $\begin{array}{l}\text { Min torque } \\
\left(\mathrm{M}_{\mathrm{L}} / \mathrm{dNm}\right)\end{array}$ & $\begin{array}{c}\Delta \text { Torque } \\
(\Delta \mathrm{T} / \mathrm{dNm})\end{array}$ \\
\hline Control SR & 7.24 & 3.13 & 24.3 & 23.19 & 1.90 & 21.29 \\
\hline $\begin{array}{l}\text { SR/MMT } \\
\text { (MMT: } 6 \text { phr) }\end{array}$ & 7.23 & 3.32 & 25.6 & 25.42 & 2.02 & 23.40 \\
\hline $\begin{array}{l}\text { SR/PS } \\
\text { (PS: } 6 \text { phr) }\end{array}$ & 11.14 & 3.25 & 12.7 & 28.37 & 2.92 & 25.45 \\
\hline $\begin{array}{l}\text { SR/PS } \\
\text { (PS: } 10 \text { phr) }\end{array}$ & 15.10 & 2.55 & 8.0 & 31.77 & 3.15 & 28.62 \\
\hline $\begin{array}{l}\text { SR/PS/MMT } \\
\text { (PS/MMT: 0.4) }\end{array}$ & 11.41 & 3.38 & 12.5 & 27.11 & 2.62 & 24.49 \\
\hline $\begin{array}{l}\text { SR/PS/MMT } \\
\text { (PS/MMT: 1.0) }\end{array}$ & 10.26 & 3.11 & 14.0 & 30.90 & 2.98 & 27.92 \\
\hline $\begin{array}{l}\text { SR/PS/MMT } \\
\text { (PS/MMT: 1.7) }\end{array}$ & 13.42 & 2.45 & 9.1 & 33.79 & 3.43 & 30.36 \\
\hline
\end{tabular}


TABLE 3: Mechanical properties of control rubber and nanocomposites

\begin{tabular}{|c|c|c|c|c|c|c|c|}
\hline Compound Ter & $\begin{array}{l}\text { ensile strength } \\
\text { (MPa) }\end{array}$ & $\begin{array}{c}\text { Elongation at break } \\
(\%)\end{array}$ & $\begin{array}{l}\text { Young's modulus } \\
\text { (MPa) }\end{array}$ & $\begin{array}{l}\text { M100 I } \\
\text { (MPa) }\end{array}$ & $\begin{array}{l}\mathrm{M} 300 \mathrm{O} \\
(\mathrm{MPa})\end{array}$ & $\begin{array}{l}\text { Hardness } \\
\text { (Shore A) }\end{array}$ & $\begin{array}{l}\text { Stored energy density at break } \\
\qquad\left(\mathrm{mJ} / \mathrm{m}^{3}\right)\end{array}$ \\
\hline Control SR & 0.40 & 756 & 0.30 & 0.20 & 0.30 & 18.5 & 2.42 \\
\hline SD & \pm 0.04 & \pm 31 & \pm 0.01 & \pm 0.01 & \pm 0.01 & \pm 0.01 & \pm 0.32 \\
\hline $\begin{array}{l}\text { SR/PS } \\
\text { (PS:6 phr) }\end{array}$ & 1.15 & 779 & 0.54 & 0.33 & 0.55 & 22.0 & 5.04 \\
\hline SD & \pm 0.06 & \pm 36 & \pm 0.01 & \pm 0.01 & \pm 0.01 & \pm 0.4 & \pm 0.43 \\
\hline $\begin{array}{l}\text { SR/PS } \\
\text { (PS:10 phr) }\end{array}$ & 1.44 & 801 & 0.61 & 0.36 & 0.62 & 26.0 & 6.27 \\
\hline SD & \pm 0.14 & \pm 86 & \pm 0.01 & \pm 0.01 & \pm 0.01 & \pm 0.3 & \pm 1.28 \\
\hline $\begin{array}{l}\text { SR/MMT } \\
\text { (MMT:6 phr) }\end{array}$ & 0.69 & 756 & 0.39 & 0.25 & 0.41 & 20.0 & 3.24 \\
\hline SD & \pm 0.02 & \pm 29 & \pm 0.01 & \pm 0.01 & \pm 0.01 & \pm 0.3 & \pm 0.15 \\
\hline $\begin{array}{l}\text { SR/PS/MMT } \\
\text { (PS/MMT:0.4) }\end{array}$ & 0.97 & 752 & 0.5 & 0.25 & 0.41 & 21.5 & 4.30 \\
\hline SD & \pm 0.07 & \pm 31 & \pm 0.01 & \pm 0.01 & \pm 0.01 & \pm 0.31 & \pm 0.57 \\
\hline $\begin{array}{l}\text { SR/PS/MMT } \\
\text { (PS/MMT:1.0) }\end{array}$ & 1.26 & 768 & 0.60 & 0.35 & 0.60 & 24.4 & 5.50 \\
\hline SD & \pm 0.04 & \pm 31 & \pm 0.01 & \pm 0.01 & \pm 0.01 & \pm 0.56 & \pm 0.37 \\
\hline $\begin{array}{l}\text { SR/PS/MMT } \\
\text { (PS/MMT:1.7) }\end{array}$ & 1.92 & 950 & 0.70 & 0.40 & 0.72 & 27.0 & 9.80 \\
\hline SD & \pm 0.12 & \pm 46 & \pm 0.02 & \pm 0.01 & \pm 0.01 & \pm 0.23 & \pm 0.9 \\
\hline
\end{tabular}

SD: Standard Deviation. 
TABLE 4: Dissipated energy of the control SR and nanocomposites at different levels of elongation. Results from the first cycle.

\begin{tabular}{lcc}
\hline Compound & \multicolumn{2}{c}{ Energy dissipation $\left(\mathrm{mJ} / \mathrm{m}^{3}\right)$} \\
& $200 \%$ strain & $400 \%$ strain \\
\hline Control SR & 26 & 97 \\
SR/MMT & 36 & 139 \\
(MMT: 6 phr) & 28 & 105 \\
SR/PS & & 199 \\
(PS: 6 phr) & 41 & \\
SR/PS & & 123 \\
(PS: 10 phr) & 30 & \\
SR/PS/MMT & & 194 \\
(PS/MMT: 0.4) & 41 & \\
SR/PS/MMT & & \\
(PS/MMT: 1.0) & 60 & \\
SR/PS/MMT & & \\
(PS/MMT: 1.7) & & \\
\hline
\end{tabular}




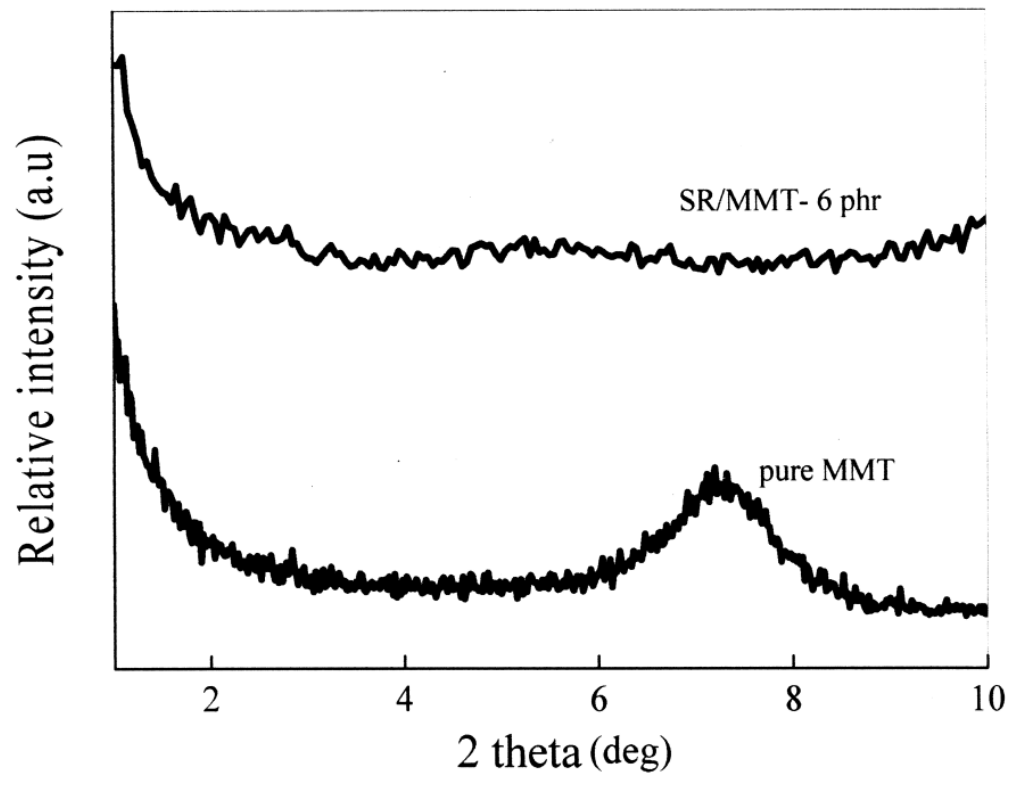

FIG.1: XRD spectra of the pure MMT and SR/MMT nanocomposite with 6 phr MMT. 


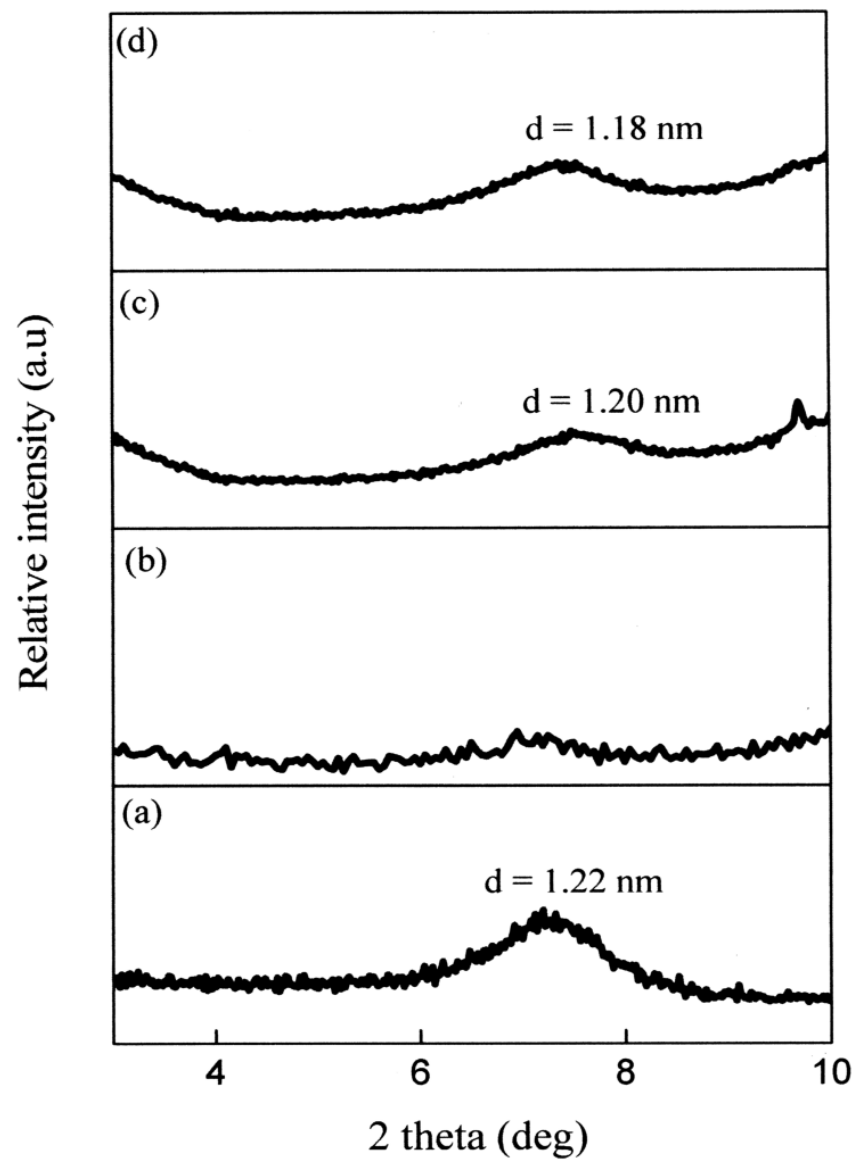

FIG. 2: XRD spectra of (a) pure MMT, (b) SR/MMT with 6 phr MMT (c) SR/PS/MMT (PS/MMT:0.4) and (d) SR/PS/MMT (PS/MMT:1.7). 

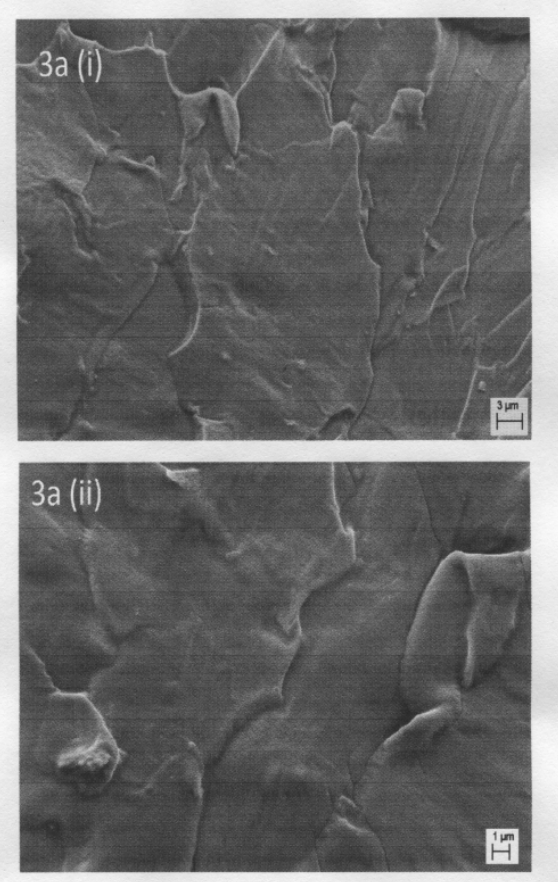

FIG. 3a: SEM micrograph showing the dispersion of 6 phr MMT in the rubber (i) $5000 \mathrm{x}$ mag and (ii) $10,000 \mathrm{x}$ mag.
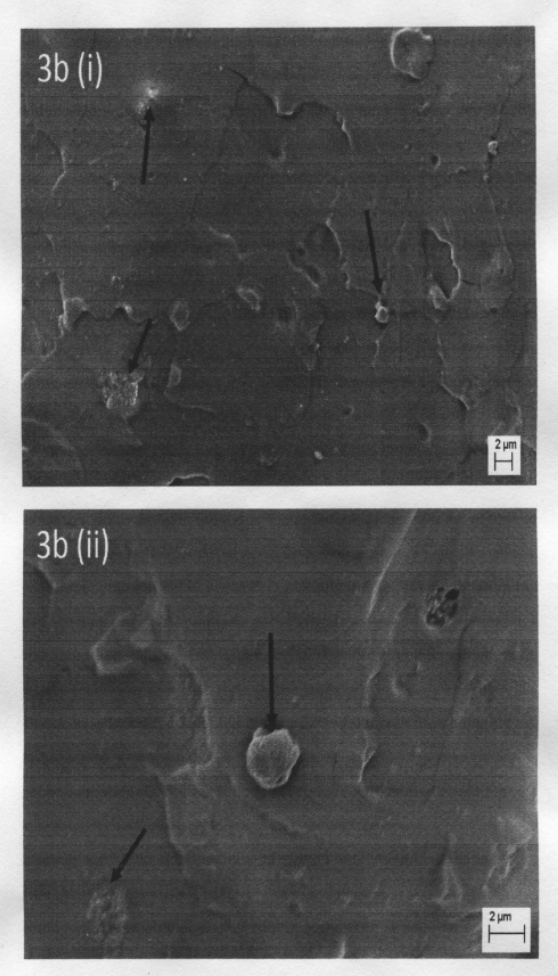

FIG 3b: SEM micrograph showing the dispersion of 6 phr PS in the rubber (i) 5000x mag and (ii) 10,000x mag. Aggregates are visible. 


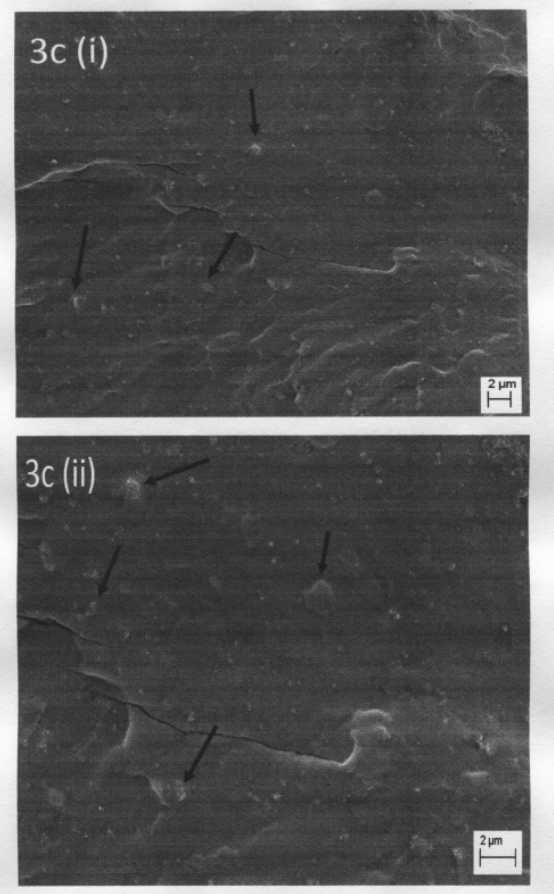

FIG. 3c: SEM micrograph showing the dispersion of $10 \mathrm{phr}$ PS in the rubber (i) 5000x mag and (ii) 10,000x mag. Aggregates are visible.
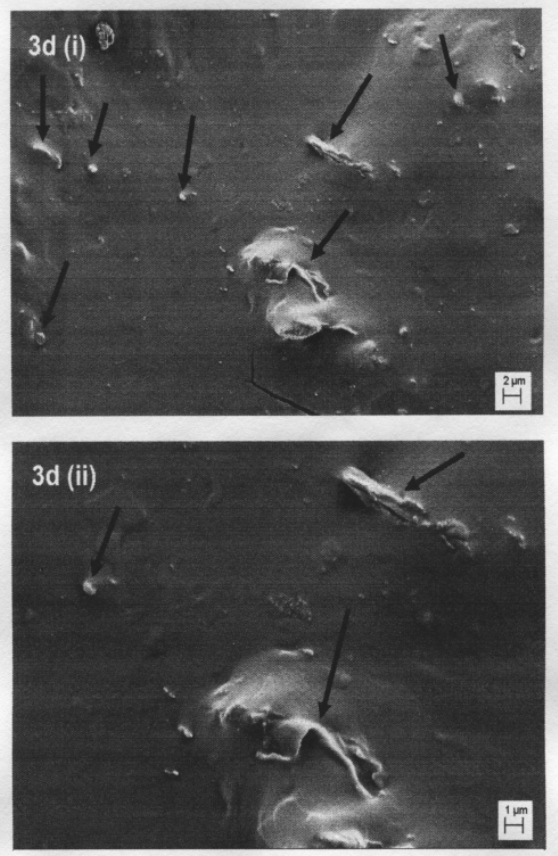

FIG. 3d: SEM micrographs showing dispersion of PS/MMT hybrid filler in the SR/PS/MMT nanocomposite (PS/MMT:0.4) (i) 5000x mag, (ii) 10,000x mag. PS and MMT aggregates are separately visible. 


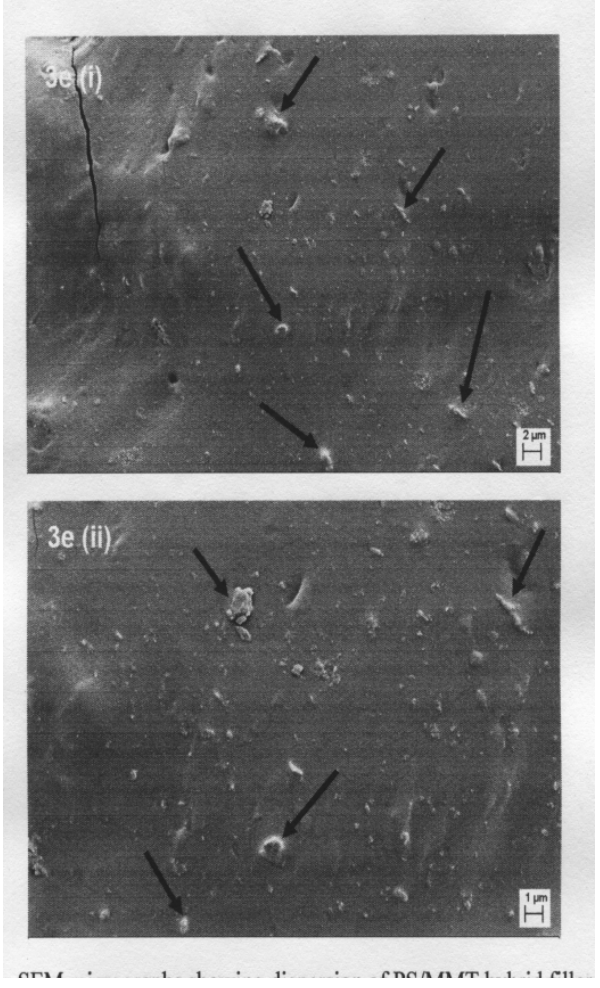

FIG. 3e: SEM micrographs showing dispersion of PS/MMT hybrid filler in the SR/PS/MMT nanocomposite (PS/MMT:1.7). (i) 5000x mag, (ii) 10,000x mag. PS and MMT aggregates are separately visible. 


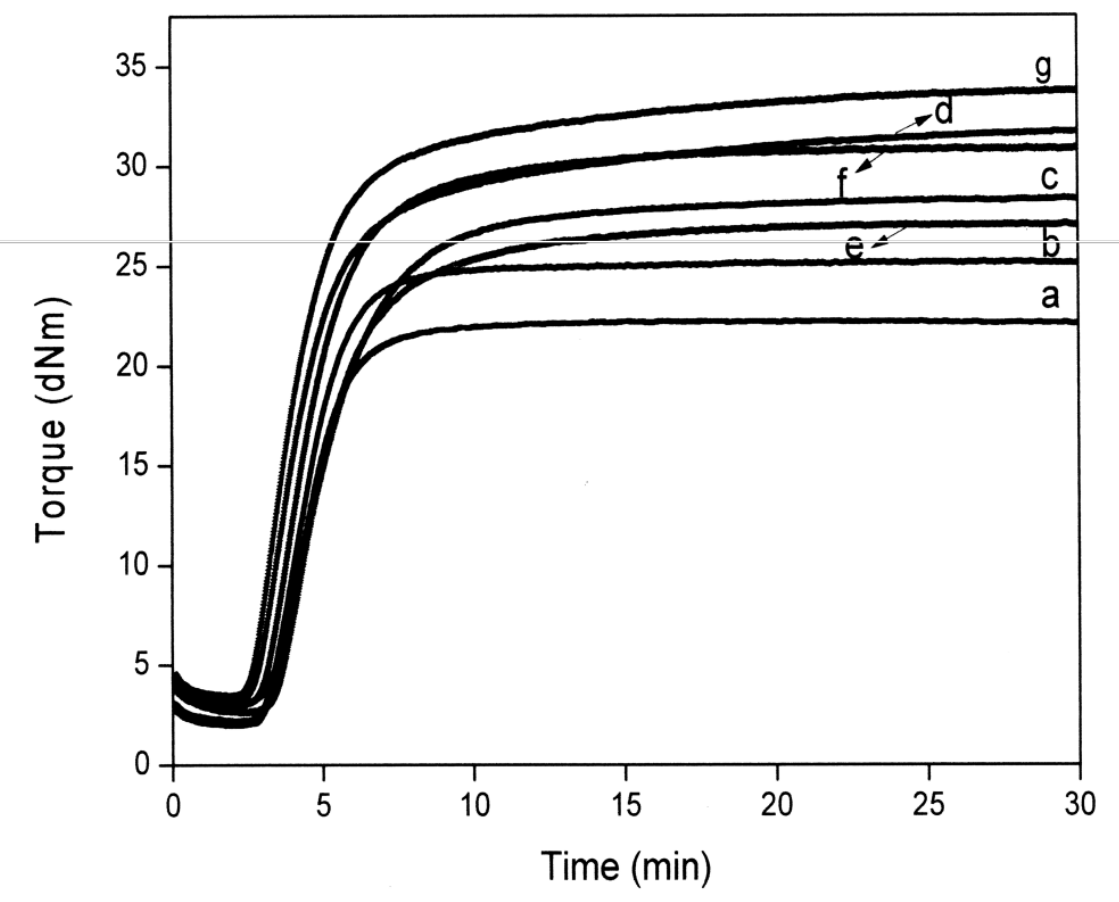

FIG. 4: Rheometer curves of (a) pure SR, (b) SR/MMT with 6 phr MMT, (c) SR/PS with $6 \mathrm{phr}$ PS, (d) SR/PS with $10 \mathrm{phr}$ PS, (e) SR/PS/MMT (PS/MMT: 0.4), (f) SR/PS/MMT (PS/MMT: 1.0), (g) SR/PS/MMT (PS/MMT:1.7). 

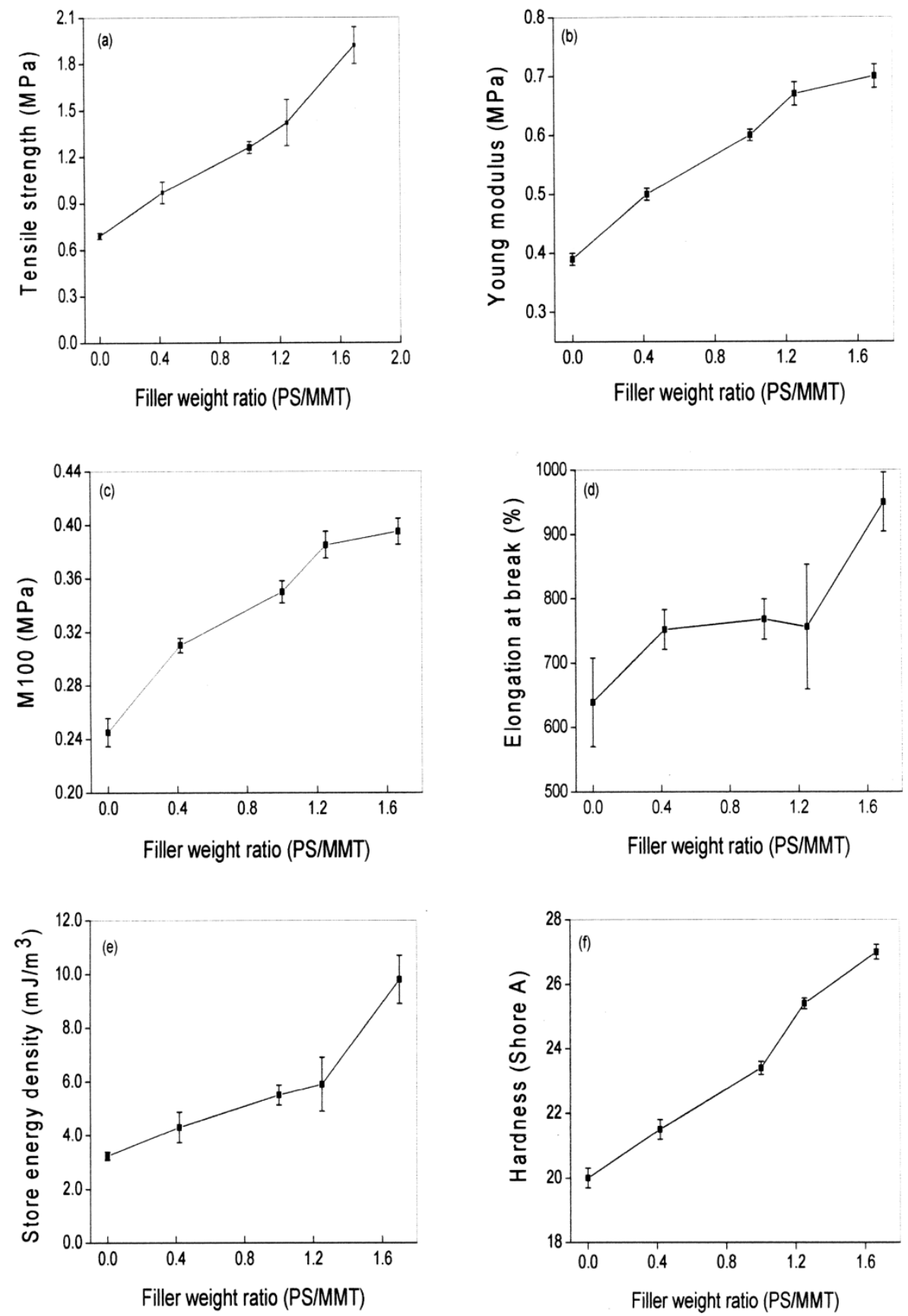

FIG. 5: (a) tensile strength, (b) Young's modulus, (c) M100, (d) elongation at break (e) stored energy density and (f) hardness of the SR/PS/MMT nanocomposites as a function of PS/MMT hybrid filler weight ratio. Note that the results at 0 filler weight ratio are for the SR/MMT nanocomposite with 6 phr MMT. 


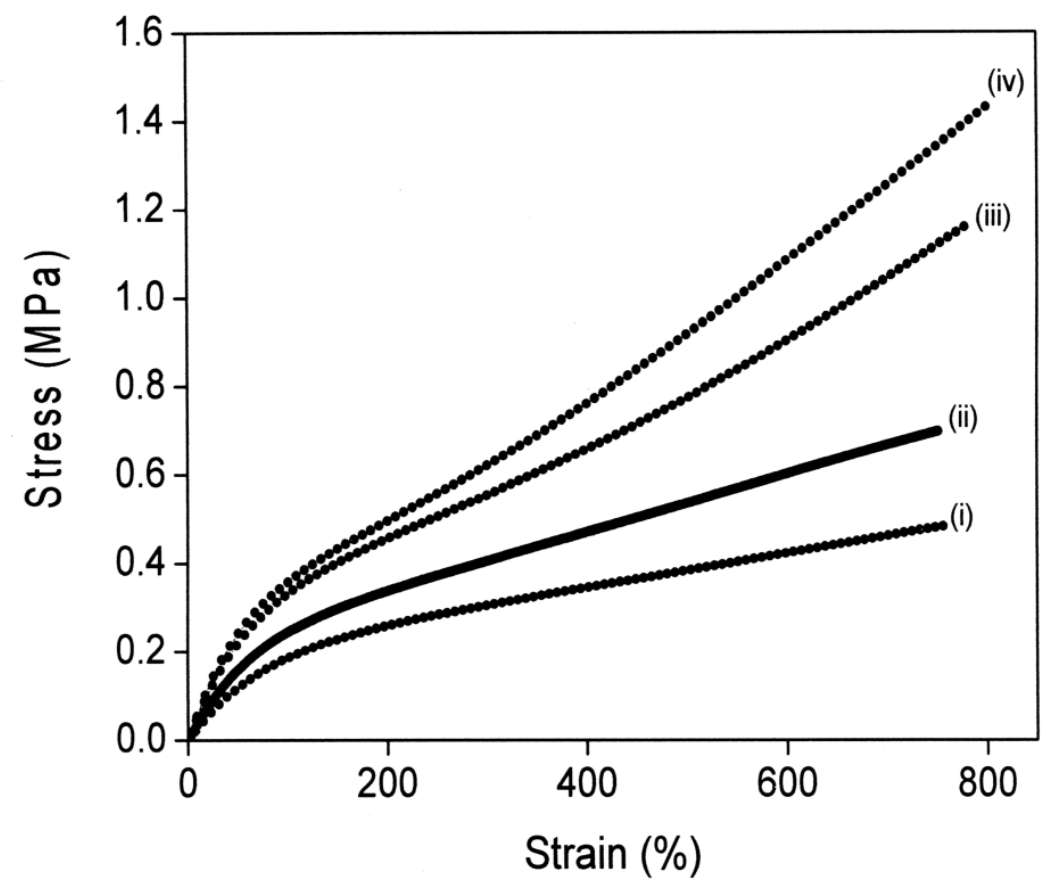

FIG. 6a: Stress-strain curves of pure SR and SR/MMT and SR/PS nanocomposites. i) pure SR, ii) SR/MMT (MMT:6 phr), iii) SR/PS (PS:6 phr), iv) SR/PS (PS:10 phr). 


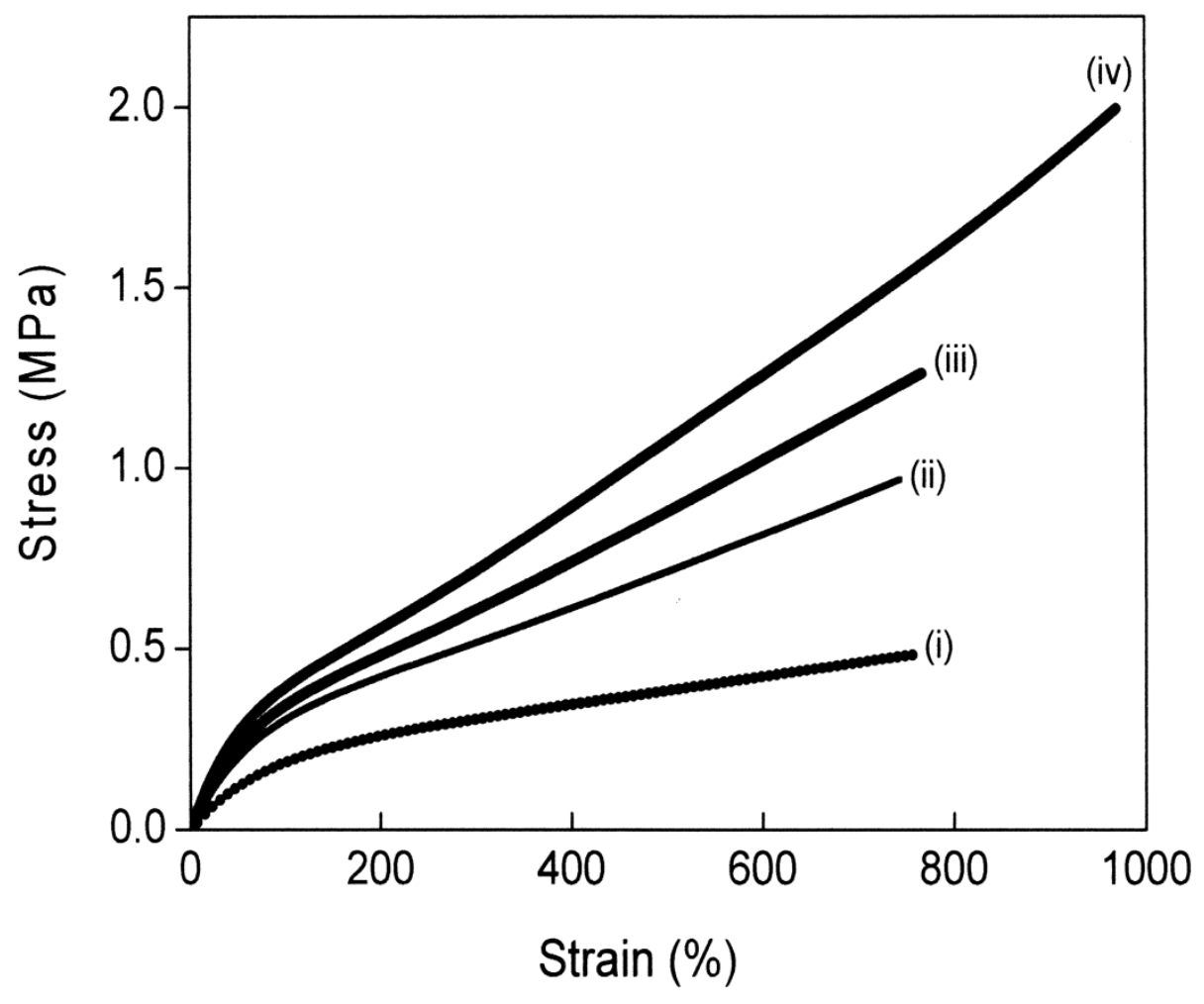

FIG. 6b: Stress-strain curves of pure SR and SR/PS/MMT nanocomposites. i) Pure SR, ii) SR/PS/MMT (PS/MMT:0.4), iii) SR/PS/MMT (PS/MMT:1.0), iv) SR/PS/MMT (PS/MMT:1.7). 


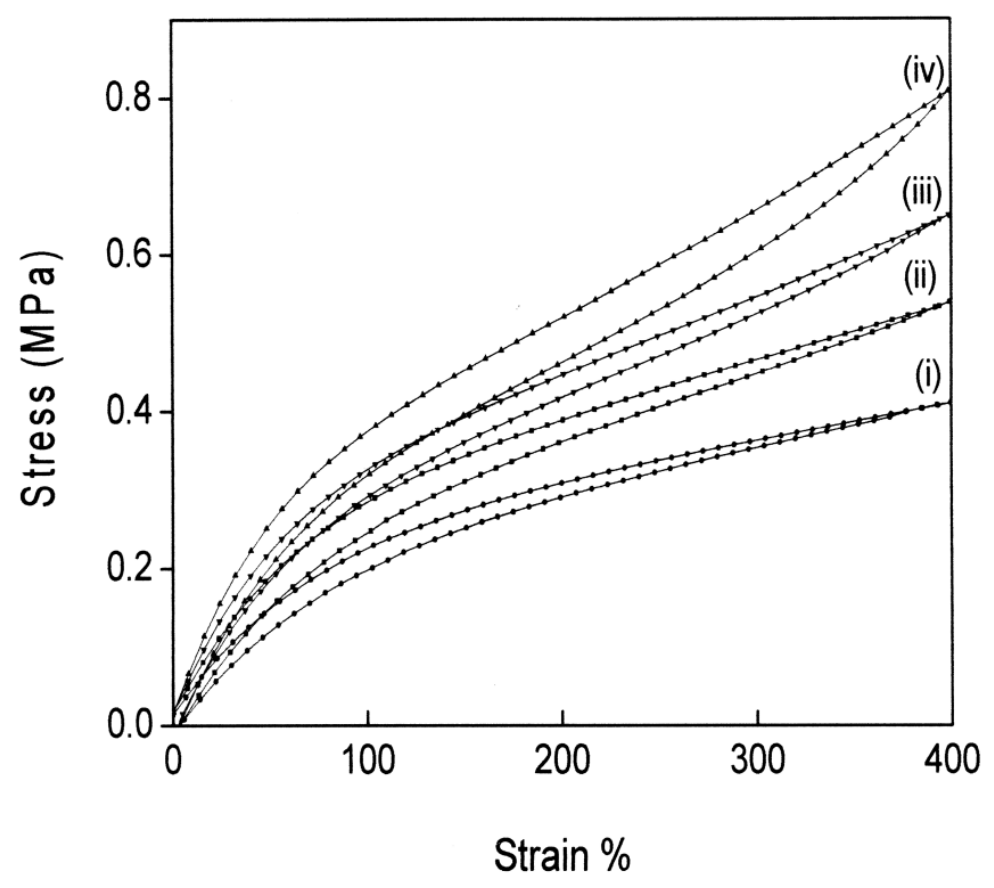

FIG. 7a: Stress-strain curves of the (i) pure SR, (ii) SR/MMT nanocomposite with 6 phr MMT, (iii) SR/PS nanocomposite with 6 phr PS, (iv) SR/PS nanocomposite with 10 phr PS. 


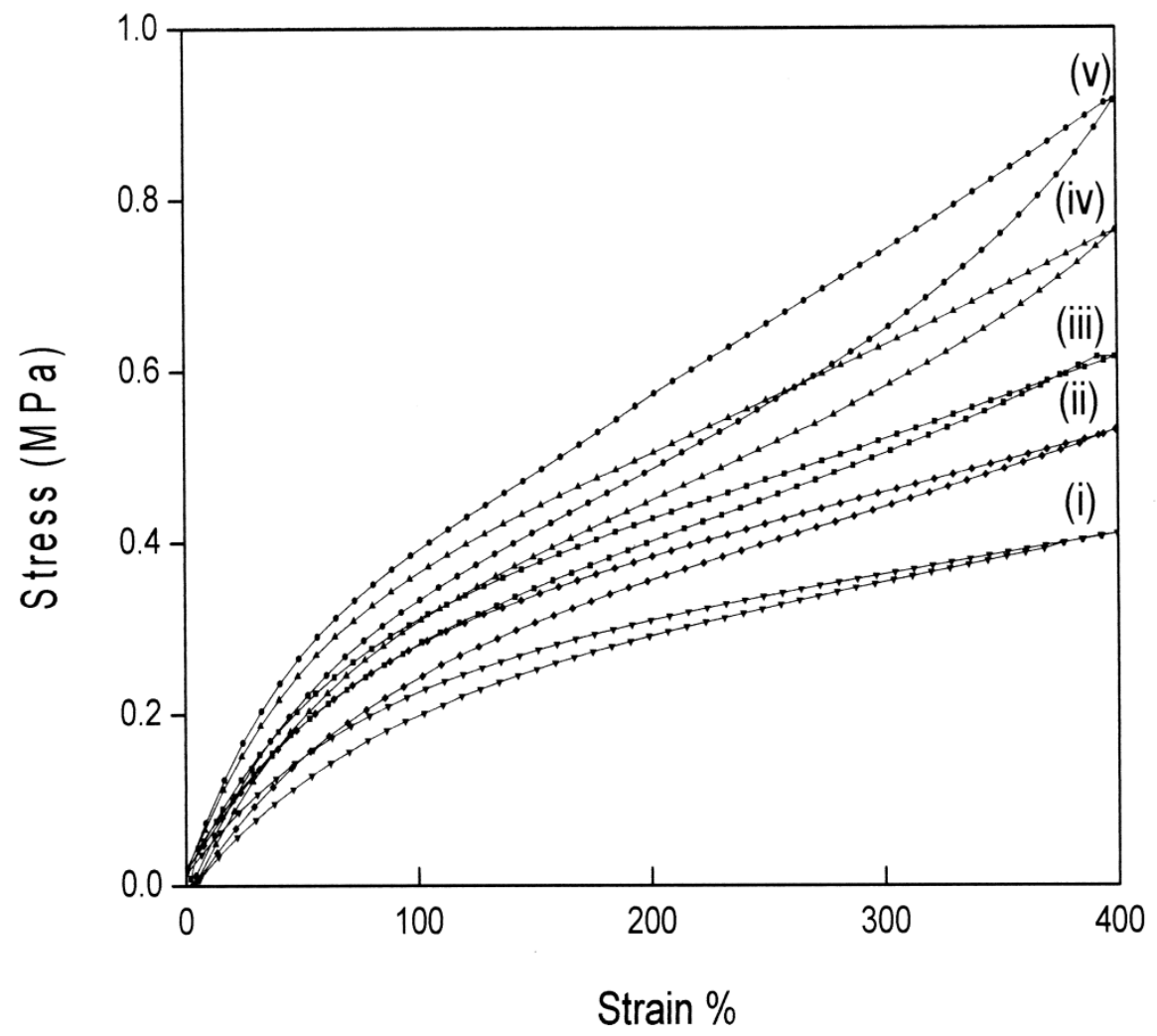

FIG. 7b: Stress-strain curves of the (i) pure SR, (ii) SR/MMT nanocomposite with $6 \mathrm{phr}$ MMT, (iii) SR/PS/MMT nanocomposite (PS/MMT: 0.4), (iv) SR/PS/MMT nanocomposite (PS/MMT:1.0), (v) SR/PS/MMT nanocomposite (PS/MMT:1.7). 